Fukushima J. Med. Sci.,

Vol. 60, No. 1, 2014

[Original Article]

\title{
ISOLATION AND AUTOXIDATION PROFILE OF FISH MYOGLOBIN FROM HOKI (MACRURONUS MAGELLANICUS)
}

\author{
GEN KOBAYASHI ${ }^{1)}$, TORU MIZUGUCHI ${ }^{2)}$ and ARIKI MATSUOKA ${ }^{1)}$ \\ ${ }^{1)}$ Department of Biology, Fukushima Medical University, Fukushima, Japan, ${ }^{2)}$ Central Research Labora- \\ tory, Nippon Suisan Kaisha, Ltd., Tokyo, Japan
}

(Received January 24, 2014, accepted February 19, 2014)

\begin{abstract}
Myoglobin is known to be present exclusively in cardiac and red skeletal muscles, but not in white skeletal muscles. Thus, to date, only a few studies on myoglobin from fish species with white flesh have been reported. For comparative examination, we directly isolated myoglobin from cardiac muscle of hoki (Macruronus magellanicus), one of the most important commercial fish species with white muscle. The ferrous myoglobin was separated from its ferric met-form by anion exchange column chromatography. The absorption spectra of hoki myoglobin were similar to those of bigeye tuna skeletal myoglobin, in both oxy- and met-forms. However, hoki oxymyoglobin was found to be susceptible to autoxidation in $0.1 \mathrm{M}$ buffer $(\mathrm{pH} 7.2)$ at $25^{\circ} \mathrm{C}$, with its rate being more than 3 times higher than that of bigeye tuna oxymyoglobin.
\end{abstract}

Key words : fish myoglobin, hoki, oxymyoglobin, autoxidation

\section{INTRODUCTION}

In vertebrates, myoglobin $(\mathrm{Mb})$, a mobile carrier of oxygen, is known to be present in cardiac and red skeletal muscles, and plays an important role in maintaining aerobic metabolism both as an oxygen store and as a facilitator of oxygen diffusion ${ }^{1)}$. Studies of teleost fish Mbs have provided important information on molecular evolution of vertebrate $\mathrm{Mb}$, because of their remarkable species diversity compared to any other class of vertebrate ${ }^{2)}$. Structural and stability properties of fish $\mathrm{Mb}$ has been investigated mainly in fish with red muscles, such as tuna and mackerel, in which $\mathrm{Mb}$ is found in high concentration $^{2-5)}$. Only a few studies, however, have reported on $\mathrm{Mb}$ from fish species with white skeletal muscle $^{6)}$.

Hoki (Macruronus magellanicus), which is closely related to cod, is one of the most important commercial fish species with white muscle. It is found in the Southeast Pacific and Southwest Atlantic Oceans, off the coast of southern Chile and Argentina, at depths ranging from 60 to $600 \mathrm{~m}^{7}$.
In this paper, we described procedures for isolating oxygen binding ferrous $\mathrm{Mb}$ (oxyMb) directly from hoki cardiac muscle, which contains large amounts of $\mathrm{Mb}$, almost comparable to those in mammalian cardiac muscles. Using this native preparation, we examined for the first time the autoxidation rate of hoki oxyMb to ferric $\mathrm{Mb}$ (metMb).

\section{MATERIALS AND METHODS}

\section{Oxymyoglobin preparation}

According to the purification procedure for tuna $\mathrm{Mb}^{3)}$, hoki $\mathrm{Mb}$ from cardiac muscles was prepared at low temperatures $\left(0-4^{\circ} \mathrm{C}\right)$. In order to avoid rapid autoxidation of oxyMb, $\mathrm{CO}$-saturated buffers were used during the procedure. The frozen hearts (ca. $50 \mathrm{~g}$ ) were thawed quickly and minced twice in a 2 -fold volume (w/v) of $10 \mathrm{mM}$ Tris- $\mathrm{HCl}$ buffer $(\mathrm{pH}$ 8.7) containing $1 \mathrm{mM}$ EDTA. After extraction for $30 \mathrm{~min}$, insoluble materials were removed by centrifugation. The extract was then fractionated between $70 \%$ and $90 \%$ saturation with ammonium sul-

Correspondence : Ariki Matsuoka, PhD E-mail : ariki@fmu.ac.jp

https://www.jstage.jst.go.jp/browse/fms http://www.fmu.ac.jp/home/lib/F-igaku/ 
fate at $\mathrm{pH}$ 8. The $\mathrm{Mb}$ precipitate was centrifuged, dissolved in a minimum volume of $2 \mathrm{mM}$ Tris- $\mathrm{HCl}$ buffer ( $\mathrm{pH}$ 8.7) containing $1 \mathrm{mM}$ EDTA, and dialyzed against the same buffer. The crude Mb solution was then passed through a Sephadex G-50 (GE Healthcare Japan) column $(4.5 \times 90 \mathrm{~cm})$ with a $2 \mathrm{mM}$ Tris- $\mathrm{HCl}$ buffer ( $\mathrm{pH}$ 8.7) containing $1 \mathrm{mM}$ EDTA to separate $\mathrm{Mb}$ from hemoglobin. The hoki $\mathrm{Mb}$ was applied to a DEAE-cellulose column, which had been equilibrated with a $2 \mathrm{mM}$ Tris- $\mathrm{HCl}$ buffer at $\mathrm{pH}$ 8.7. After contaminant proteins were washed out completely, metMb was eluted with a $5 \mathrm{mM}$ Tris$\mathrm{HCl}$ buffer (pH 8.7) for the first. Then, the ferrous $\mathrm{CO}$-form was eluted out with a $10 \mathrm{mM}$ Tris- $\mathrm{HCl}$ buffer ( $\mathrm{pH}$ 8.7), and immediately stored in liquid nitrogen until use. For autoxidation experiments, hoki oxyMb was produced from the $\mathrm{CO}$-form in an $\mathrm{O}_{2}{ }^{-}$ saturated buffer ( $\mathrm{pH}$ 8.7), by flash-photolysis for 3 min using 300-watts photoreflector lamp (Toshiba) in an ice bath $\left(0-4^{\circ} \mathrm{C}\right)^{8}$. The concentration of the $\mathrm{Mb}$ was determined, after conversion into cyanomet-form, using an absorption coefficient of 9.0 $\mathrm{mM}^{-1} \mathrm{~cm}^{-1}$ at $540 \mathrm{~nm}$. This coefficient value was obtained on the basis of the pyridine hemochromogen method ${ }^{9)}$.

\section{Autoxidation rate measurement}

The rate of autoxidation of oxyMb was measured in a $0.1 \mathrm{M}$ buffer $(\mathrm{pH} 7.2)$ at $25^{\circ} \mathrm{C}$, according to our standard procedure ${ }^{3)}$. For example, a $900 \mu 1$ solution of the appropriate buffer was placed in a test tube and incubated in a water bath maintained at 25 $\pm 0.1^{\circ} \mathrm{C}$. The reaction was started by adding $100 \mu \mathrm{l}$ of fresh oxyMb solution $(100-150 \mu \mathrm{M})$, and the changes in the absorption spectrum over 450-700 $\mathrm{nm}$ were recorded at measured intervals of time. For the final state of the runs, oxyMb was completely converted into its ferric met-form by the addition of potassium ferricyanide. Absorption spectra were recorded on a Hitachi U-3300 spectrophotometer equipped with a thermostatically controlled cell holder (within $\pm 0.1^{\circ} \mathrm{C}$ ).

\section{RESULTS}

\section{Oxymyoglobin preparation}

In the procedures for isolating native ferrous $\mathrm{Mb}$, an essential step was the chromatographic separation from ferric metMb by a DEAE-cellulose column. The metMb was eluted out with a $5 \mathrm{mM}$ buffer, and then ferrous $\mathrm{CO}-\mathrm{Mb}$ was obtained with a 10 $\mathrm{mM}$ buffer (Fig. 1). Obtained oxy- and met-Mbs

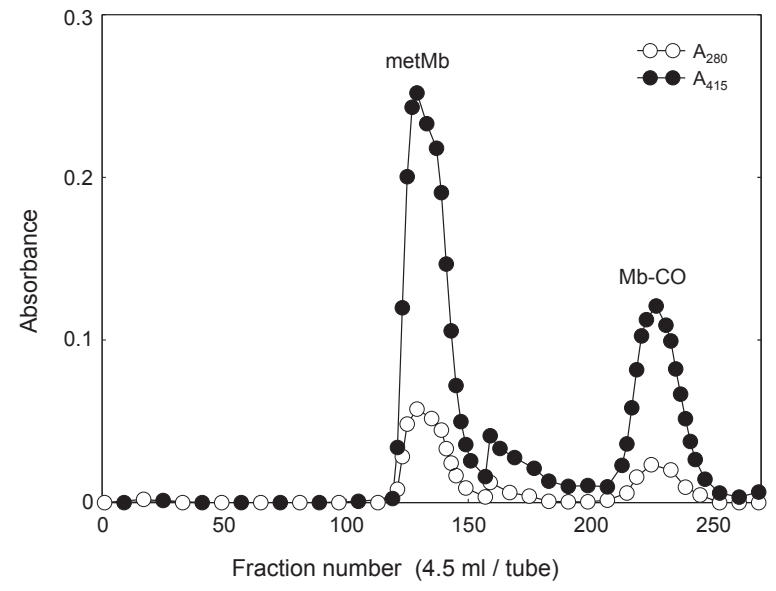

Fig. 1. DEAE-cellulose column chromatography of hoki myoglobin. After gel filtration, $\mathrm{Mb}$ solution was applied to a DEAE-cellulose column $(2.0 \times 10$ $\mathrm{cm})$ equilibrated with a $2 \mathrm{mM}$ Tris- $\mathrm{HCl}$ buffer $(\mathrm{pH}$ 8.7) under $\mathrm{CO}$-saturated condition. The metMb was eluted out with a $5 \mathrm{mM}$ buffer, and then $\mathrm{Mb}^{-}$ $\mathrm{CO}$ was eluted with a $10 \mathrm{mM}$ buffer.

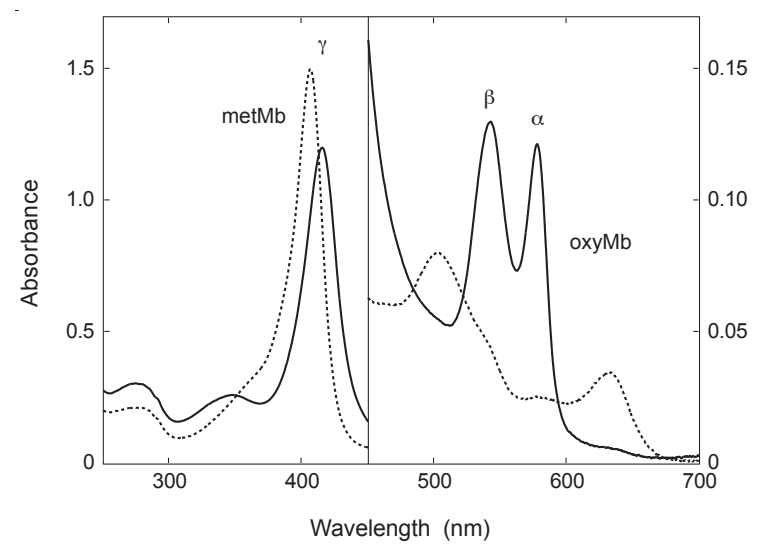

Fig. 2. Absorption spectra of the hoki oxyMb (bold line) and metMb (broken line). The concentration was $10 \mu \mathrm{M}$ for each form. The oxy-form was produced from the $\mathrm{CO}$-form by flash-photolysis in an $\mathrm{O}_{2}$-saturated buffer ( $\mathrm{pH}$ 8.7). The spectrum of the met-form was obtained at $\mathrm{pH}$ 7.0. The expanded scale was used for the visible spectra.

showed a single band in SDS-polyacrylamide gel electrophoresis, respectively, with the molecular mass of about $15 \mathrm{kDa}$. The oxygenated form was produced from the $\mathrm{CO}$-form by flash photolysis in an $\mathrm{O}_{2}$-saturated buffer at $\mathrm{pH}$ 8.7.

Fig. 2 represents the absorption spectra of hoki $\mathrm{Mb}$ both in the oxy-form (bold line) and in the acidic met-form (broken line). The absorption maxima of hoki oxyMb were $577 \mathrm{~nm}$ (12.2), $542 \mathrm{~nm}$ (13.0), 415 $\mathrm{nm}(120)$ and $280 \mathrm{~nm}$ (30.7). The values in parentheses are the extinction coefficients in $\mathrm{mM}^{-1} \mathrm{~cm}^{-1}$ 
A

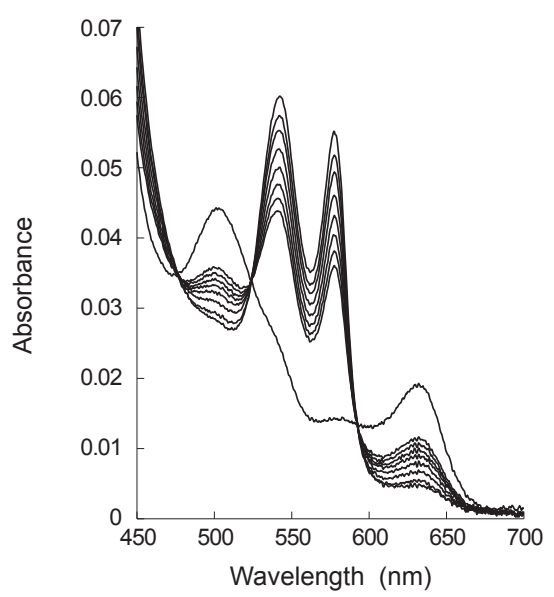

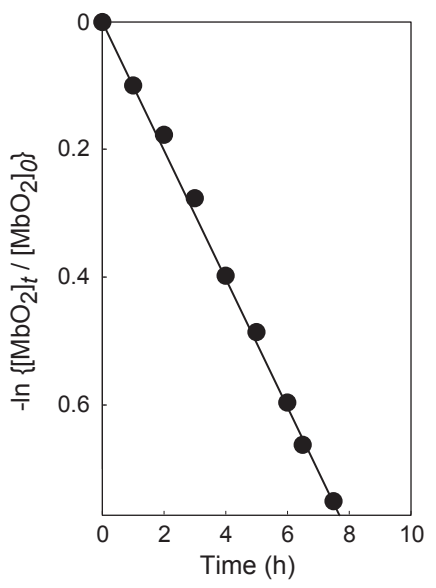

Fig. 3A. Spectral changes of hoki oxyMb with time in a $0.1 \mathrm{M}$ phosphate buffer (pH 7.2 ) at $25^{\circ} \mathrm{C}$. Scans were made at $1 \mathrm{~h}$ intervals. The final spectrum was obtained by the addition of potassium ferricyanide.

Fig. 3B. The first-order plot for the autoxidation of hoki oxyMb in a $0.1 \mathrm{M}$ phosphate buffer $(\mathrm{pH} 7.2)$ at $25^{\circ} \mathrm{C}$.

at each wavelength. The $\gamma$-peak of hoki metMb was higher than that of the oxyMb with an absorbance ratio of $\gamma_{\text {met }} \gamma_{\text {oxy }}=1.25$.

\section{Stability property of hoki oxymyoglobin}

Under air-saturated conditions, oxyMb $\left(\mathrm{MbO}_{2}\right)$ is oxidized easily to metMb with generation of the superoxide anion as

$$
\mathrm{MbO}_{2} \stackrel{k_{\mathrm{obs}}}{\longrightarrow} \operatorname{metMb}+\mathrm{O}_{2}^{-}
$$

where $k_{\text {obs }}$ represents the first-order rate constant observed at a given $\mathrm{pH}^{10)}$. Therefore, the rate of autoxidation is given by

$$
\frac{-\mathrm{d}\left[\mathrm{MbO}_{2}\right]}{\mathrm{d} t}=k_{\mathrm{obs}} \cdot\left[\mathrm{MbO}_{2}\right] .
$$

Fig. 3A shows such example of spectral changes with time for the autoxidation reaction of hoki oxyMb in a $0.1 \mathrm{M}$ phosphate buffer $(\mathrm{pH} 7.2)$ at $25^{\circ} \mathrm{C}$. This process of autoxidation was followed by a plot of experimental data as a $-\ln \left(\left[\mathrm{MbO}_{2}\right]_{t} /\left[\mathrm{MbO}_{2}\right]_{0}\right)$ versus time $t$, where the ratio of oxyMb concentration after time $t$ to that at time $t=0$ can be monitored by the absorbance changes at $577 \mathrm{~nm}$ ( $\alpha$-peak of hoki oxyMb). Its first-order plot, Fig. 3B, is also shown to obtain the rate constant of $k_{\mathrm{obs}}=9.1 \times 10^{-2} \mathrm{~h}^{-1}$ from the slope of the line. Regarding the half-life for conversion of oxyMb to metMb, this corresponded to $8 \mathrm{~h}$ for hoki fish.

\section{DISCUSSION}

The reversible and stable binding of oxygen to the heme iron(II) is the basis of $\mathrm{Mb}$ function. However, the oxygenated form of $\mathrm{Mb}$ is known to be oxidized easily to ferric metMb, which cannot bind molecular oxygen and is therefore physiologically inactive, with generation of the superoxide anion $^{10,11)}$. Using a variety of native oxyMbs isolated directly from various sources, the reaction mechanism for autoxidation of oxyMbs has been investigated $^{12,13)}$.

In the present study, we directly isolated $\mathrm{Mb}$ from the cardiac muscle of hoki fish and examined its autoxidation reaction. Because of its rapid autoxidation, it was essential to convert the ferrousform of hoki $\mathrm{Mb}$ into $\mathrm{CO}$-form by the use of $\mathrm{CO}$-saturated buffers prior to the purification. The native oxygenated form was produced from the obtained $\mathrm{CO}$-form by flash photolysis ${ }^{8}$ in $\mathrm{O}_{2}$-saturated buffer.

The absorption spectra of hoki $\mathrm{Mb}$ were similar to those of bigeye tuna $\mathrm{Mb}^{3)}$. The $\gamma$-peak of hoki metMb was higher than that of the oxyMb (Fig. 2). Shikama and Matsuoka ${ }^{14)}$ have examined a dozen Mbs from various species for their spectrophotometric properties, and found that the proteins can be divided into two groups on the basis of the absorbance ratio of the $\gamma$-peak of the acidic met-form to that of the oxy-form, that is to say, the $\gamma_{\text {met }} \gamma_{\text {oxy }}$ ratio. Values higher than 1.0 were obtained for vertebrate Mbs containing the distal histidine, whereas those of less than 1.0 were seen for the ratio for the Mbs lacking this residue. It should be noted that the distal histidine, which is highly conserved in almost 
vertebrate Mbs, plays an important role in stabilization of the oxygen molecules bound to the heme iron(II) by hydrogen-bond formation. Judging from this spectral criterion, a value of $\gamma_{\text {met }} \gamma_{\text {oxy }}=1.25$ for hoki $\mathrm{Mb}$ indicates that this heme protein has the distal histidine residue.

On the other hand, it was revealed that the autoxidation rate of hoki oxyMb was higher than those of bigeye tuna oxyMb $\left(2.9 \times 10^{-2} \mathrm{~h}^{-1}\right)$ in a $0.1 \mathrm{M}$ buffer at $25^{\circ} \mathrm{C}^{3)}$. Madden et al. ${ }^{15)}$ compared the Mbs autoxidation rates of several fish species and found that the rates were closely related to body temperature; that is, Mbs from fish species with higher body temperatures were more stable to autoxidation at $\mathrm{pH} 7.5,37^{\circ} \mathrm{C}$. As the body temperature of hoki, which inhabits deep sea, may be lower than that of tunas $^{16)}$ (approximately $20-30^{\circ} \mathrm{C}$ ), our result is consistent with their report.

When compared with usual Mbs containing the distal histidine residue which had been examined so $\operatorname{far}^{17)}$, hoki oxyMb is found to be susceptible to autoxidation in a $0.1 \mathrm{M}$ buffer $(\mathrm{pH} 7.2)$ at $25^{\circ} \mathrm{C}$. The autoxidation rate differences are considered to be caused by the hydrophobicity of heme pocket ${ }^{8)}$. In addition, it has been suggested that the autoxidation property of fish Mbs is associated with the instability of its overall molecular structure ${ }^{5,18)}$. In order to understand the stability properties of hoki oxyMb in detail, analysis of the $\mathrm{pH}$ dependency of autoxidation rate as well as the determination of the primary sequence of hoki $\mathrm{Mb}$ is required.

\section{REFERENCES}

1. Wittenberg JB, Wittenberg BA. Myoglobin function reassessed. J Exp Biol, 206 : 2011-2020, 2003.

2. Marcinek DJ, Bonaventura J, Wittenberg JB, Block BA. Oxygen affinity and amino acid sequence of myoglobins from endothermic and ectothermic fish. Am J Physiol Regul Integr Comp Physiol, 280 : R1123-R1133, 2001.

3. Kitahara Y, Matsuoka A, Kobayashi N, Shikama K. Autoxidation of myoglobin from bigeye tuna fish (Thunnus obseus). Biochem Biophys Acta, 1038 : 23-28, 1990.

4. Ueki N, Ochiai Y. Structural stability of recombinant scombridae fish myoglobins. Biosci Biotechnol Biochem, 69 : 1935-1943, 2005.

5. Hasan MM, Watabe S, Ochiai Y. Structural characterization of carangid fish myoglobin. Fish
Physiol Biochem, 38 : 1311-1322, 2012.

6. Acierno R, Agnisola C, Tota B, Sidell BD. Myoglobin enhances cardiac performance in Antarctic icefish species that express the protein. Am J Physiol, 273 : R100-R106, 1997.

7. D'Amato ME. Demographic expansion and subtle differentiation in the long-tailed hake Macruronus magellanicus : evidence from microsatellite data. Mar Biotechnol, 8 : 189-201, 2006.

8. Suzuki T, Watanabe YH, Nagasawa M, Matsuoka A, Shikama K. Dual nature of the distal histidine residue in the autoxidation reaction of myoglobin and hemoglobin. Eur J Biochem, 267 : 61666174, 2000.

9. De Duve C. A spectrophotometric method for the simultaneous determination of myoglobin and hemoglobin in extracts of human muscle. Acta Chem Scand, 2 : 264-289, 1948.

10. Gotoh T, Shikama K. Generation of the superoxide radical during autoxidation of oxymyoglobin. J Biochem (Tokyo), 80 : 397-399, 1976.

11. Brantley Jr. RE, Smerdon SJ, Wilkinson AJ, Singleton EW, Olson JS. The mechanism of autooxidation of myoglobin. J Biol Chem, 268 : 6995-7010, 1993.

12. Shikama K. The molecular mechanism of autoxidation for myoglobin and hemoglobin : a venerable puzzle. Chem Rev, 98 : 1357-1373, 1998.

13. Shikama K. Nature of the $\mathrm{FeO}_{2}$ bonding in myoglobin and hemoglobin : a new molecular paradigm. Prog Biophys Mol Biol, 91 : 83-162, 2006.

14. Shikama K, Matsuoka A. Aplysia myoglobin with unusual properties : another prototype in myoglobin and haemoglobin biochemistry. Biol Rev, 69 : 233-251, 1994.

15. Madden PW, Babcock MJ, Vayda ME, Cashon RE. Structural and kinetic characterization of myoglobins from eurythermal and stenothermal fish species. Comp Biochem Physiol B, 137 : 341-350, 2004.

16. Barrett I, Hester FJ. Body temperature of yellowfin and skipjack tunas in relation to sea surface temperature. Nature, 203 : 96-97, 1964.

17. Matsuoka A, Iwaasa H, Takiguchi K, et al. Stability properties of oxymyoglobin from chicken gizzard smooth muscle. Comp Biochem Physiol B, 88 : 783-789, 1987.

18. Chow CJ, Wu JC, Lee PF, Ochiai Y. Structural and autooxidation profiles of myoglobins from three species and one hybrid of tilapia (Cichlidae, Perciformes). Comp Biochem Physiol B, 154 : 274281,2009 . 